\title{
Evolução do processo de decoração na indústria de revestimentos cerâmicos: impressão jato de tinta
}

\section{(Evolution of decoration process in ceramic coatings industry: inkjet printing)}

\author{
M. Cristiano ${ }^{1}$, V.S. Nandi ${ }^{1,2, *}$, A. Zaccaron $^{1}$ \\ ${ }^{1}$ Universidade do Extremo Sul Catarinense - UNESC, Criciúma, SC, Brasil \\ ${ }^{2}$ Programa de Pós-Graduação em Ciência e Engenharia de Materiais - PGMAT, \\ Universidade Federal de Santa Catarina-UFSC, Florianópolis, SC, Brasil \\ *vitorsnprof@gmail.com
}

\begin{abstract}
Resumo
Nos últimos 20 anos as empresas cerâmicas buscam incessantemente aprimorar suas tecnologias a fim de se tornarem mais competitivas no mercado mundial. O sistema de decoração mais utilizado na indústria cerâmica é o de rotocolor, entretanto este apresenta limitações que interferem na qualidade e produção dos revestimentos cerâmicos. Sendo assim, está aumentando o número de empresas que estão se adaptando ao novo sistema de impressão por jato de tinta para o processo de decoração de seus produtos. Baseado nesta informação este trabalho consiste em verificar as características das tintas do processo de decoração por jato de tinta e averiguar os benefícios da utilização deste sistema quando comparado ao sistema de rotocolor. O trabalho foi realizado mediante a pesquisa bibliográfica e a experimentos laboratoriais. Em laboratório foram realizados os seguintes ensaios: densidade e viscosidade em tempo de escoamento, distribuição do tamanho de partículas, determinação reológica, difratometria de raios X, microscopia óptica com aumento de 200x e colorimetria. Diante dos resultados obtidos foi possível detectar que as tintas apresentam características não nanométricas relacionadas ao contexto teórico que para ser um material nanométrico deve-se conter tamanhos de partículas todos abaixo de $100 \mathrm{~nm}$, porém as tintas apresentam como menor tamanho o valor de $105,7 \mathrm{~nm}$. Através destes resultados foi possível explicar alguns problemas técnicos que usualmente ocorrem nas impressoras e pela análise de micrografia demonstrou-se que a técnica de impressão digital é mais eficiente e proporciona maior qualidade aos produtos quando comparada à impressão por sistema de rotocolor. Detectou-se que ao alterar a temperatura de sinterização, ou seja, temperaturas necessárias perante as modificações usuais nos fornos de indústrias produtoras de placas cerâmicas de revestimento ocorre uma diferença de tonalidade em todas as cores com diferença de $\Delta \mathrm{E}$ de até 6 pontos.

Palavras-chave: rotocolor, impressão por jato de tinta, decoração cerâmica.
\end{abstract}

\begin{abstract}
Over the past 20 years ceramics companies seek incessantly improve their technologies to become more competitive in the world market. The decorative system most commonly used in ceramics industry is the rotocolor, however it has limitations that affect the quality and production of ceramic tiles. Thus, an increasing number of companies are adapting to the new printing system for inkjet decoration to their products. Based on this information this work is to verify the characteristics of the decorating process inks for inkjet and investigate the benefits of using this system when compared to rotocolor system. The work was performed by laboratory experiments and literature. The following laboratory tests were performed: density and viscosity flow time, particle size distribution, rheological determination, X-ray diffractometry, optical microscopy at 200x magnification and colorimetry. Based on these results it was possible to detect that the inks present not nanoscale features related theoretical context which to be a nanometric material is due to contain all particle sizes below $100 \mathrm{~nm}$, but the inks present as smaller value of $105.7 \mathrm{~nm}$. Through these results it was possible to explain some technical problems which usually occur in the printers and through the micrograph analysis it was demonstrated that the fingerprint technique is more efficient and provides higher quality compared to products by rotocolor printing system. It turned out that by changing the sintering temperature, ie necessary temperatures before the usual modifications in the ovens of industries producing coating ceramic tiles occurs a difference in shade in all colors of $\Delta E$ up to six points.
\end{abstract}

Keywords: rotocolor, jet printing ink, ceramic decoration.

\section{INTRODUÇÃO}

As empresas cerâmicas nos últimos 20 anos estão cada vez mais buscando aprimorar suas tecnologias visto que o mercado mundial torna-se cada vez mais exigente. Atualmente o sistema de decoração mais utilizado é o de rotocolor, porém este apresenta algumas limitações que interferem na qualidade e na produção de cerâmica 
de revestimento como: variação de tonalidade, defeitos superficiais e o tempo prolongado do setup. Entretanto, nos últimos 10 anos tem aumentado o número de empresas que utilizam a decoração de materiais através da impressora de jato de tinta, sendo que a Espanha e a Itália apresentaram importância na consolidação desta tecnologia [1].

A decoração através do processo de rotocolor consiste em uma forma de transferir desenhos ou motivos para a superfície das peças de placas cerâmicas de revestimentos [2]. Seu processo é basicamente, em depositar uma tinta sobre a peça, sendo que isso é feito por meio do cilindro que apresenta uma série de incisões. Estas incisões, mediante um sistema de rotação, são preenchidas por tinta, a qual é transferida para a peça ao ser colocada em contato com ela (Fig. 1). O desenho a ser transferido é que indicará a forma e distribuição das incisões no rolo [2]. A máquina de rotocolor apresenta como característica diferenciadora das outras máquinas (serigráficas), o fato de a decoração desenvolverse com cilindro e a peça cerâmica em movimento exatamente à mesma velocidade, ou seja, a peça não pára durante o processo de decoração [3].

Com o crescimento gradativo das empresas cerâmicas nos últimos anos, em virtude do desenvolvimeno de novas técnicas de produção, a indústria cerâmica se desenvolveu trazendo com ela novas tecnologias [3].

Os primeiros métodos para a decoração cerâmica à base de jato de tinta surgiram em Castellón, na Espanha, em 1998. Esses processos de impressão de revestimentos cerâmicos são essencialmente os mesmos que foram desenvolvidos para a impressão de papel, cartão e produtos têxteis. Sendo assim o desenvolvimento da impressão a jato de tinta apresenta um processo diferente daqueles conhecidos até o momento (serigrafia, rotocolor) [1]. Essa tecnologia faz a impressão no revestimento cerâmico sem que haja contato com a peça. O material é transportado através de correia, recebendo a impressão num processo contínuo sem interrupções. A tecnologia adotada utiliza quatro cores padrão denominada CMYK (Azul, Magenta, Amarelo e Preto) e também a possibilidade de mais uma cor, a cor branca, que aumenta a gama de efeitos de cores que oferece significantes benefícios econômicos tais como design avançado superior aos sistemas tradicionais [4].

A Durst é uma empresa, instalada na Itália, envolvida

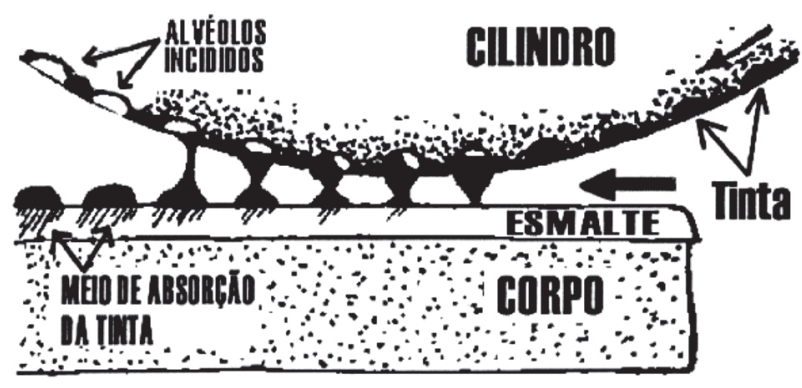

Figura 1: Princípio da decoração por rotocolor [3]. [Figure 1: Principle of rotocolor decoration [3].] no processamento de imagem desde 1936, e em 2005 disponibilizou um sistema digital comercial para a decoração de revestimentos cerâmicos utilizando tintas pigmentadas [1].

O ano de 2008 foi denominado "o ano da revolução digital para o setor cerâmico" visto que houve uma expansão muito rápida na decoração de revestimentos cerâmicos pela impressão jato de tinta [1].

A impressão do desenho ocorre através de bicos injetores, que produzem gotas de tinta que podem ser provenientes de dois métodos diferentes: 1 ) jato de tinta contínuo: um jato de tinta contínuo é emitido a partir de um bocal e divide-se em uma corrente de gotas esféricas de tintas. Um eletrodo carrega eletricamente por indução cada gota que é direcionada por forças eletrostáticas para escrever pontos sobre a peça. Este método é utilizado pelas indústrias para a impressão de data e códigos de lote, e na indústria cerâmica para a rotulagem das embalagens e para imprimir alguns códigos de identificação nas bordas dos revestimentos, porém não é usado para a decoração de revestimentos; 2) gota por demanda: a gota de tinta é injetada sob demanda pela indução de um pulso de pressão transiente em uma câmera de tinta por trás do bico. Esta tecnologia é empregada em todas as impressoras de jato de tinta para a decoração de revestimentos cerâmicos [1].

Comparando a impressão digital com os métodos tradicionais de decoração, esse sistema apresenta as seguintes vantagens:

- Designs variados e flexibilidade: permite desenvolver novos produtos e desenvolver novas soluções personalizadas. Novas amostras de desenho também podem ser criadas muito mais rápidas com baixo custo. Desenhos e conceitos únicos agora são possíveis; $100 \%$ decorado - canto a canto: Todo o revestimento da superfície é impresso corretamente até as bordas da peça;

- Decoração total em materiais com relevo: quanto à decoração de revestimentos irregulares (com relevos médios e fortes), garante-se perfeita definição de todas as partes;

- Demanda de impressão e ensaios: Já que com essa tecnologia não é necessário trocar as cores fisicamente, a qualidade de impressão ou os metros quadrados não têm influência no custo de produção e no tempo de setup;

- Maior qualidade na impressão e maior variedade de cores: Proporciona uma qualidade de impressão superior às técnicas convencionais. Sistema de gerenciamento das cores integrado com a combinação de cores dos modelos originais; Custos reduzidos com administração de tintas e armazenamento: Uma vez que o sistema digital cria automaticamente todas as cores e tonalidades necessárias com apenas 4 cores, elimina todas as atividades envolvidas na preparação, gerenciamento, controle e armazenamento das cores, fixadores, solventes, entre outros, e elimina a necessidade de rolos de impressão e telas [4].

As tintas utilizadas na impressão digital são provenientes de nano pigmentos orgânicos ou inorgânicos, insolúveis, quimicamente e fisicamente inertes ao substrato ou ligantes, com tamanho de partícula menor que $100 \mathrm{~nm}^{5}$. A palavra nanopartícula, provém do grego, nano significa anão, prefixo utilizado nas ciências para designar uma parte em 
um bilhão, sendo que um nanômetro corresponde a um bilionésimo de metro [5]. As tintas apresentam restrições sobre o tamanho máximo a fim de evitar o entupimento do bico, além disso apresentam efeito sobre a cor e, também, existe a necessidade de estabilidade em longo prazo para evitar sua sedimentação [1].

As partículas nanométricas são obtidas através de metodologias complexas, além de apresentarem risco para a saúde humana através da inalação e contato com a pele. As cerâmicas têm apresentado características mecânicas de superfície e resistência química superiores quando utilizados óxidos com partículas nanométricas de zircônia e alumina [6].

No Brasil, iniciou-se a primeira produção com impressão de jato de tinta em novembro de 2009 com a empresa Ceusa Revestimentos Cerâmicos, e já existem mais de 30 máquinas instaladas. Esta nova tecnologia garante uma produção e qualidade muito maior relacionada aos processos conhecidos, mas, por ser algo extremamente novo, trouxe consigo alguns problemas e dificuldades para as indústrias, principalmente no quesito de tintas, pois empregam- se para esta tecnologia partículas nanométricas. Baseado neste contexto o objetivo desse trabalho de pesquisa foi verificar as características das tintas do processo de decoração por jato de tinta e averiguar os benefícios da utilização da decoração por jato de tinta quando comparada à impressão pelo sistema de rotocolor.

\section{MATERIAIS E MÉTODOS}

A metodologia empregada na realização deste trabalho consiste na coleta e análise das tintas da Ink Jet (impressora jato de tinta para placas cerâmicas de revestimentos) comparando-as com a aplicação de rotocolor contemplando as seguintes etapas apresentadas na Fig. 2:

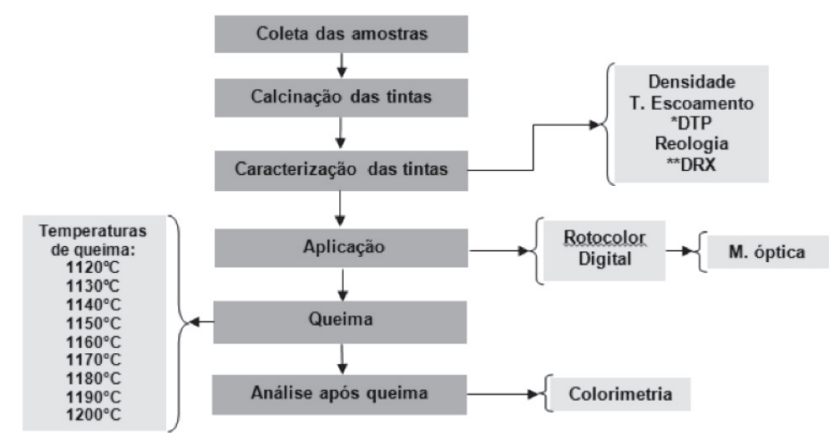

*DTP (Distribuição do tamanho de partículas); **DRX (difratometria de raios $X)$.

Figura 2: Fluxograma das atividades experimentais que foram executadas durante o desenvolvimento do trabalho.

[Figure 2: Flowchart of experimental activities that were performed during work development.]

Inicialmente coletou-se $500 \mathrm{~mL}$ de cada tinta do sistema de impressão digital para os estudos necessários. As tintas coletadas foram na cor magenta, azul, amarelo e preto. Em seguida realizaram- se os ensaios de densidade e viscosidade (em tempos de escoamento) das amostras. As medidas das densidades das tintas foram realizadas com picnômetro (Servitech), com volume $100 \mathrm{~mL}$ e tara $200 \mathrm{~g}$. Assim, calculou-se a densidade das tintas identificando sua massa através do preenchimento e fechamento completo do picnômetro e através da Equação A:

$$
\mathrm{d}=\frac{\mathrm{m}}{\mathrm{v}}
$$

na qual $\mathrm{d}=$ densidade da barbotina $\left(\mathrm{g} / \mathrm{cm}^{3}\right), \mathrm{m}=$ massa $\mathrm{da}$ barbotina $(\mathrm{g})$, e v = volume da barbotina $\left(\mathrm{cm}^{3}\right)$.

A análise do tempo de escoamento também pode ser considerada um teste para o controle do processo de caracterização das tintas. Este teste foi realizado com auxílio do Copo Ford (Servitech) com abertura de $4 \mathrm{~mm}$. Em seguida, uma quantidade definida de $50 \mathrm{~g}$ de cada amostra de tinta, foi calcinada individualmente em forno muflado Jung com taxa de aquecimento de $90^{\circ} \mathrm{C}$ por um período de $5 \mathrm{~h}$ e outro ciclo na temperatura de $600^{\circ} \mathrm{C}$ e um período de $1 \mathrm{~h}$, com taxa de aquecimento de $1{ }^{\circ} \mathrm{C} / \mathrm{min}$. Este procedimento foi repetido 5 vezes para conferir a quantidade de tinta necessária para realização dos ensaios posteriores.

A distribuição do tamanho de partículas foi determinada em um equipamento Malvern Instr. zethasizer-nano séries.

A determinação reológica das tintas azul, magenta, amarelo e preta foi realizada num viscosímetro rotacional com geometria cilíndrica concêntrica (VT550, ThermoHaake, Polylab System/52p Rheomex). As medidas foram realizadas a $25^{\circ} \mathrm{C}$. A taxa de cisalhamento variou entre 0 a $1200 \mathrm{~s}^{-1}$.

Posteriormente, para determinação das fases, uma quantidade de cada amostra calcinada e passante em \# 200 mesh $(75 \mu \mathrm{m})$ foi encaminhada para ensaio de difratometria de raios X (DRX) em um difratômetro Siemens D5000, com radiação Cuka, potência de $40 \mathrm{kV}-25 \mathrm{~mA}$.

Para avaliar a aplicabilidade do método tradicional de aplicação de tintas (Rotocolor) com o sistema mais atual de jato de tinta, foi feita observação em microscópio metalográfico (Leica DMILM) com aumento de 200x.

No intuito de realizar um estudo relacionando modificação de tonalidade com o aumento da temperatura, foi realizado um range de queima com temperaturas pré-definidas que oscilaram entre $1120{ }^{\circ} \mathrm{C}$ e $1200{ }^{\circ} \mathrm{C}$, com aumento de $10+-3$ ${ }^{\circ} \mathrm{C}$ por queima em um ciclo de $40 \mathrm{~min}$. Para esta etapa foram aplicadas 9 placas cerâmicas de revestimento no método de decoração por Ink Jet das 4 cores estudadas. Em seguida foram encaminhadas para o processo de queima em um forno laboratorial tendo como combustível gás natural.

Após a queima foi realizado o ensaio de colorimetria em todas as placas com as diferentes temperaturas em um calorímetro Hunter Lab (Color QUEST); a escala de leitura foi o sistema de coordenadas cromáticas com base no espaço de cor CIELAB L* $a^{*} b^{*}$, no qual $L^{*}$ mede a luminosidade e tem uma variação de branco (100) a preto (0), a* é uma indicação de cromaticidade, na direção do verde é negativo (-a*) se for 0 (zero) é cinzento e se for na direção do vermelho é positivo $\left(+a^{*}\right)$ e b* é uma indicação de cromaticidade, na direção do azul é negativo (-b*) se for 0 (zero) é cinzento e se for na direção do amarelo é positivo $\left(+b^{*}\right)$. Para comparação dos 
resultados foram utilizadas como padrão ás cores queimadas na temperatura de $1160^{\circ} \mathrm{C}$, temperatura esta mais comumente utilizada no processo de fabricação de placas cerâmicas de revestimento pelo método de monoqueima.

\section{RESULTADOS E DISCUSSÃO}

Os resultados obtidos para a densidade e viscosidade em tempos de escoamento estão descritos na Tabela I:

Os resultados apresentados para as tintas não possuem variações significativas em suas viscosidades em tempos

Tabela I - Resultados dos ensaios de densidade e viscosidade em tempos de escoamento.

[Table I - Test results for density and viscosity flow times.]

\begin{tabular}{ccc}
\hline Amostras & $\begin{array}{c}\text { Densidade } \\
\left(\mathrm{g} / \mathrm{cm}^{3}\right)\end{array}$ & $\begin{array}{c}\text { Tempo escoamento } \\
(\mathrm{s})\end{array}$ \\
\hline Preta & 1,23 & 16,3 \\
Azul & 1,16 & 17,3 \\
Magenta & 1,06 & 17,3 \\
Amarelo & 1,16 & 16,0 \\
\hline
\end{tabular}

de escoamento, a variação máxima foi de $1 \mathrm{~s}$. A tinta preta comparada com as outras tintas utilizadas no trabalho apresenta a maior densidade, ou seja, na mesma quantidade de fornecimento para todas as tintas que é de $10 \mathrm{~L}$, esta apresenta o maior peso $12,3 \mathrm{~kg}$ em contrapartida à tinta magenta que apresenta o menor peso $10,06 \mathrm{~kg}$. Baseadas nesta informação, as empresas que utilizam estas tintas devem ficar atentas a este ensaio e adaptá-lo como forma de controle, para que seja possível conferir e controlar as possíveis variações nas trocas de lotes, pois se houver qualquer diferença, pode interferir diretamente na cor do produto e também nas pressões e parâmetros de trabalho da impressora.

A distribuição do tamanho de partículas da Fig. 3 mostra que todas as tintas ficaram em uma faixa de tamanho entre $105,7 \mathrm{~nm}$ a $3600 \mathrm{~nm}$, este tamanho reduzido de partícula faz com que as tintas sejam reativas, já que sua área superficial em virtude deste tamanho pequeno é muito grande. Baseado no conceito de que considera-se um material nanométrico todo aquele que possui tamanho de partículas menor que $100 \mathrm{~nm}$ [7], as tintas utilizadas para fabricação de placas cerâmicas de revestimento pelo método de impressão digital não são nanométricas, como usualmente tratadas são submicrométricas.

Uma informação importante que pode ser extraída deste resultado está ligada diretamente ao mecanismo da impressora em trabalho, pois cada tinta em funcionamento apresenta uma característica típica de provocar algum problema, como por exemplo, a tinta amarela que apresenta entupimento das peneiras do pulpo (polvo) seguida da tinta azul o que provoca o aumento da pressão do sistema acionando o mecanismo de segurança e parando o equipamento. A tinta Magenta, apresenta problemas de corrosão e queima de circuitos

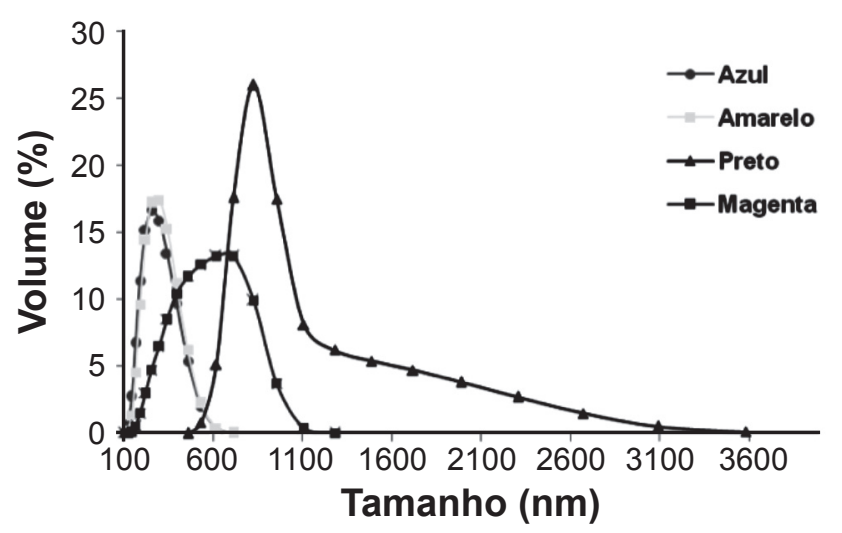

Figura 3: Resultado da distribuição do tamanho de particulas das tintas utilizadas na realização do trabalho (média de 5 amostras ). [Figure 3: Results of the particle size distribution of the inks used in work performance (average of 5 samples).]

eletrônicos quando ocorre vazamento, já a tinta preta danifica o sistema de desaeração (desaerador). Assim, acredita-se que o entupimento das peneiras seja característico da alta reatividade entre as partículas das tintas amarela e azul pelo seu tamanho de partícula ser inferior às demais, também deve ser comentado que a tinta amarela é a que possui o maior consumo, acarretando o maior desgaste e possíveis problemas. A corrosão da tinta Magenta não é característica de sua distribuição de partícula, mas a danificação do desaerador pela tinta preta está diretamente relacionada pelo seu tamanho de partículas ser muito maior, já que o desaerador tem característica de um filtro.

Baseado nestas informações acredita-se que para as tintas amarela e azul necessitariam de um aditivo com características mais eficientes quanto a defloculação de suas partículas, já para a tinta preta, um desaerador com sistema filtrante diferenciado (mais aberto) perante as outras tintas seria mais eficaz para o trabalho diário, pois sabe-se que para cada troca de desaerador perde-se aproximadamente $30 \mathrm{~min}$ de produtividade.

O comportamento reológico das tintas apresenta grande importância sobre a qualidade da decoração do produto. Avaliando os gráficos apresentados na Fig. 4, observa-se que todas as tintas não apresentaram comportamento dependente do tempo (tixotropia), apresentam comportamento Newtoniano. A viscosidade de todas as tintas encontra-se em valores muito baixos (0,02-0,09 Pa.s), isso se faz necessário devido ao tipo de aplicação, onde as tintas são transportadas por filtros e mecanismos que não aceitariam uma viscosidade maior.

A Fig. 5 apresenta os difratogramas de raios $\mathrm{X}$ das tintas estudadas. A tinta azul apresenta majoritariamente as seguintes fases cristalinas: ferro/alumínio $\left(\mathrm{Fe}_{2} \mathrm{Al}_{2} \mathrm{O}_{4}\right.$, arquivo 34-0192) e magnésio/alumínio $\left(\mathrm{MnAl}_{2} \mathrm{O}_{4}, 29-0880\right)$. A tinta magenta possui ouro ( $\mathrm{Au}, 4-0784)$ e prata ( $\mathrm{Ag}, 4-0783)$, além disso, percebe-se certa quantidade de fase amorfa neste material, devido, provavelmente, a algum tipo de material amorfo existente em sua composição. A tinta amarela apresentou em seu difratograma as fases de silicato de zircônio $\left(\mathrm{ZrSiO}_{4}\right.$, 


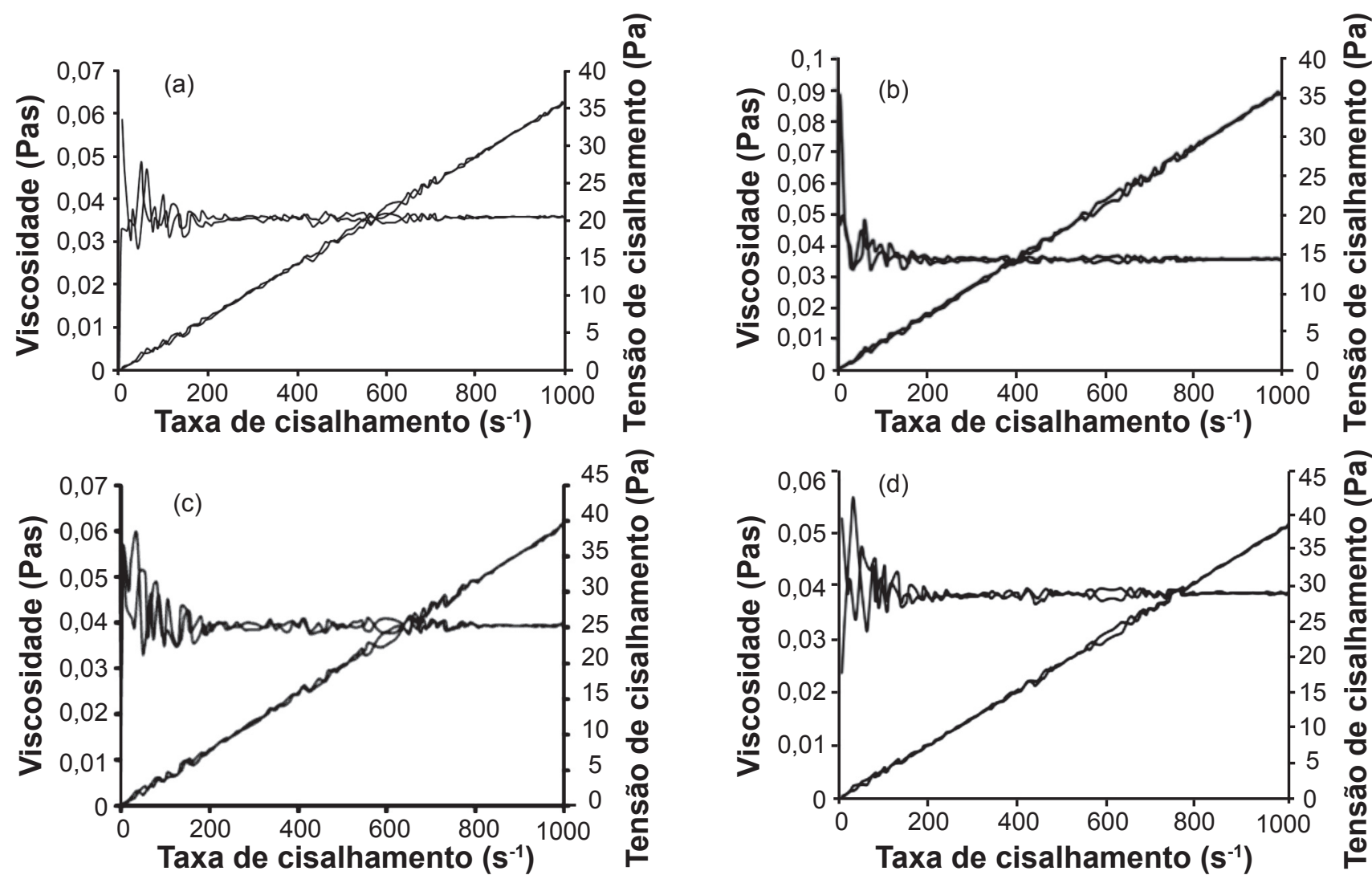

Figura 4: Curvas de tensão de cisalhamento para suspensões de tintas cerâmicas aplicadas em decoração de placas cerâmicas de revestimentos por impressão (Ink Jet). (a) azul, (b) Magenta, (c) amarelo, (d) preto.

[Figure 4: Curves of shear stress for suspensions of ceramic paints applied in coatings of ceramic plates decorating for printing (Ink Jet). (a) Blue (b) Magenta (C) yellow, (d) black.]
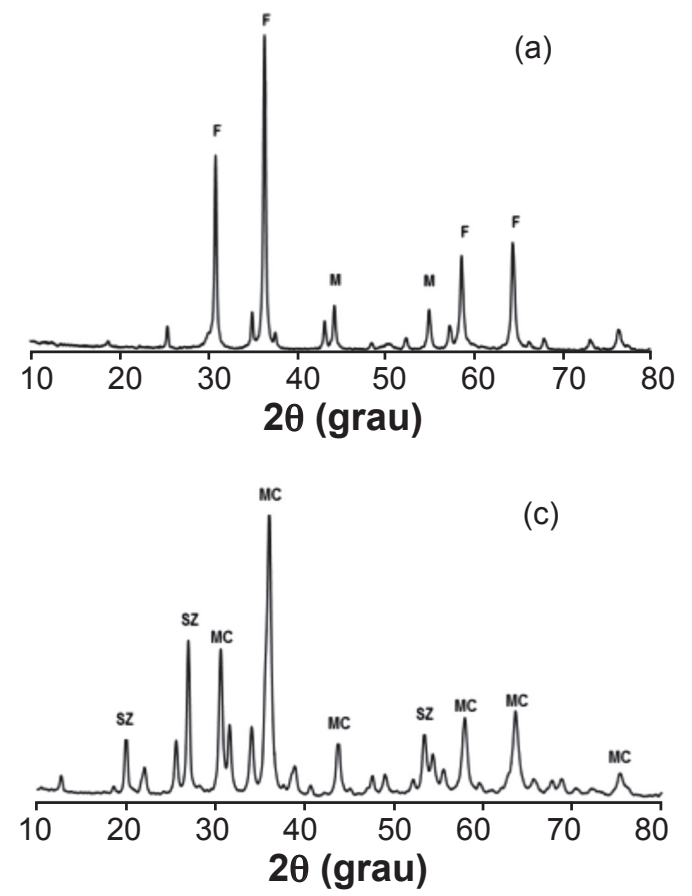

(b)

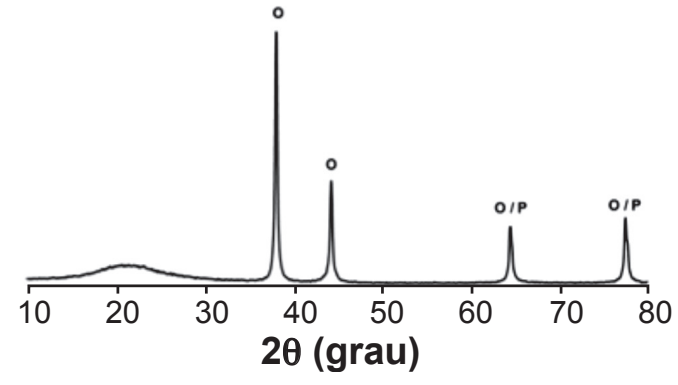

(d)

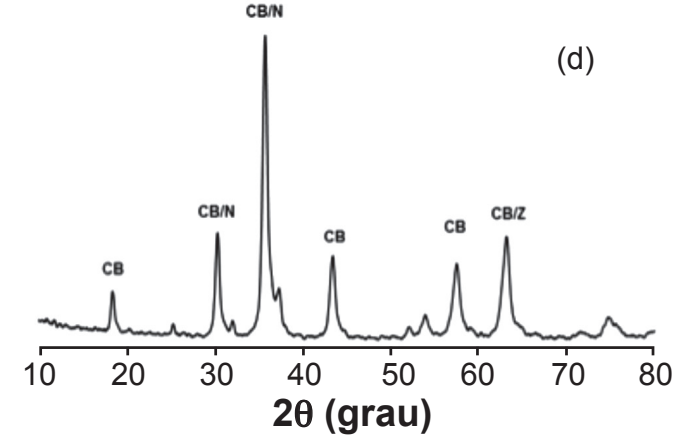

Figura 5: Difratogramas de raios X das tintas estudadas. (a) Azul; (b) Magenta; (c) Amarelo; (d) Preto. F: Ferro/ $\mathrm{Aluminio}\left(\mathrm{Fe} \mathrm{Al}_{2} \mathrm{O}_{4}\right.$ ); $\mathrm{M}$ : Magnésio/Aluminio $\left(\mathrm{MnAl}_{2} \mathrm{O}_{4}\right)$; O: Ouro (Au); P: Prata (Ag); SZ: silicato de zircônio $\left(\mathrm{ZrSiO}_{4}\right)$; $\mathrm{MC}$ : Maganês/Cobalto $\left(\mathrm{MnCo}_{2} \mathrm{O}_{4}\right)$; CB: Cobalto/Cromo $\left(\mathrm{CoCr}_{2} \mathrm{O}_{4}\right)$; N: Ferro/Niquel $\left(\mathrm{NiFe}_{2} \mathrm{O}_{4}\right)$; Z: Zinco/Manganês $\left(\mathrm{ZnMnO}_{3}\right)$.

[Figure 5: X-ray diffraction patterns of paints. (a) Blue; (b) Magenta; (c) Yellow; (d) Black. F: Iron / Aluminum (Fe $\left.\mathrm{Al}_{2} \mathrm{O}_{0}\right)$; M: Magnesium

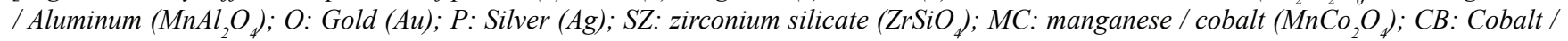
Chromium ( $\left.\mathrm{CoCr}_{2} \mathrm{O} 4\right)$; $\mathrm{N}$ : Iron / Nickel $\left(\mathrm{NiFe}_{2} \mathrm{O}_{4}\right)$; $\mathrm{Z}$ : Zinc/Manganese $\left(\mathrm{ZnMnO}_{3}\right)$.] 

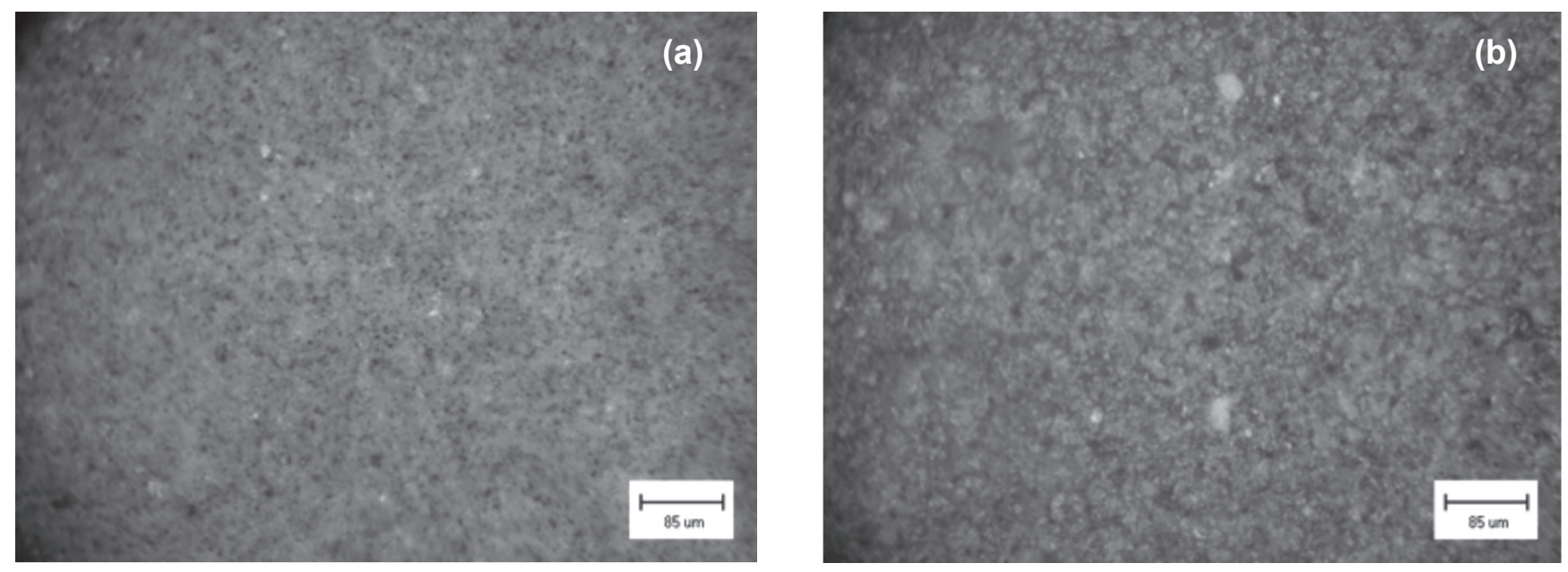

Figura 6: Fotografia de duas placas cerâmicas aplicadas com diferentes tipos de decoração com aumento de 200 x: (a) Aplicação de tinta pelo método de rotocolor; (b) Aplicação de tinta pelo método de impressão digital.

[Figure 6: Photograph of two ceramic plates applied with different kinds of decoration with a $200 x$ : (a) Application of paint by the method of rotocolor; (b) Application of paint by digital printing method.]

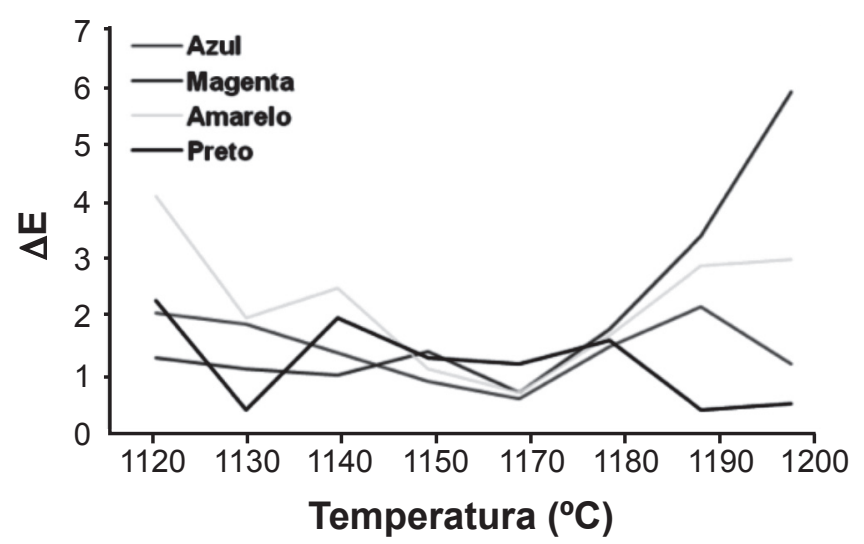

Figura 7: Valores de $\Delta \mathrm{E}$ nas amostras de tintas em diferentes temperaturas.

[Figure 7: $\Delta E$ values in the samples of inks at different temperatures.]

6-266) e manganês/cobalto $\left(\mathrm{MnCo}_{2} \mathrm{O}_{4}, 23-1237\right)$ e por último a tinta preta possui majoritariamente as fases de cobalto/ cromo $\left(\mathrm{CoCr}_{2} \mathrm{O}_{4}, 22-1084\right)$, ferro/níquel $\left(\mathrm{NiFe}_{2} \mathrm{O}_{4}, 10-0325\right)$ e zinco/manganês $\left(\mathrm{ZnMnO}_{3}, 19-1461\right)$. Todas as fases para cada tinta representam suas cores após o processo de sinterização, estas fases são comuns mesmo nos pigmentos utilizados para o processo de fabricação de tintas para rotocolor, a única diferença é que não possuem fases de sílica. Com este ensaio foi possível relacionar o porquê a tinta magenta causa danos elétricos nos equipamentos quando ocorre algum vazamento. Provavelmente está relacionada às fases de ouro existentes em sua composição, sabendo-se que o ouro é um dos melhores condutores de eletricidade, ou seja, quando ocorre algum tipo de vazamento desta tinta, essa provoca os danos elétricos e até mesmo a queima total do equipamento. Na Fig. 6b é possível observar a eficiência do processo de decoração por impressão digital (Ink Jet) comparada ao processo de decoração por rotocolor (rolo de silicone) (Fig. 6a), onde a quantidade de pontos por $\mathrm{mm}^{2}$ é muito maior, sendo impossível verificar parte do esmalte branco. $\mathrm{Na}$ aplicação por rotocolor (Fig. 6a), é possível verificar os pontos de cada cor e também que o tamanho de cada ponto é muito maior, bem como, parte do esmalte branco. Através do range de queima realizado para cada tinta, foi possível construir o gráfico apresentado na Fig. 7, onde foi avaliada a diferença de tonalidade em função da temperatura através do valor de $\Delta \mathrm{E}$, comparando a temperatura padrão de $1160{ }^{\circ} \mathrm{C}$, sendo que a metodologia da calorimetria é a mais adequada para o controle de tonalidades na fabricação de revestimentos cerâmicos. Observou-se que a tinta amarela e magenta são as que apresentam maior variação de tonalidade com a mudança de temperatura $\left(1120\right.$ a $\left.1200{ }^{\circ} \mathrm{C}\right)$. Percebe-se que quando a temperatura encontra-se em $1170{ }^{\circ} \mathrm{C}$ as tintas apresentam valores mais próximos do padrão. Porém a variação do $\Delta \mathrm{E}$ nos outros pontos apresentam diferenças significativas entre cada tinta, ou seja, para a condição utilizada na maioria das indústrias de placas cerâmicas de revestimento onde muita das vezes utiliza-se de mudanças de temperatura nos fornos no objetivo de acerto de curvaturas, podem estar provocando variações significativas em suas tonalidades. Onde a tinta magenta apresenta a maior diferença de tonalidade para as temperaturas mais altas.

\section{CONSIDERAÇÕES FINAIS}

Uma vez que uma empresa reconheça o valor estratégico do desenvolvimento de novos produtos para manter vantagem competitiva e resolva adaptar uma cultura empresarial de incentivo à inovação, a mesma precisa se organizar, estabelecendo alguns sistemas que auxiliarão a gestão competente de projetos de novos produtos. A tendência da crescente globalização, o avanço tecnológico, a mudança das necessidades dos clientes, o aumento da diversidade de produtos, e a redução do ciclo de vida desses produtos no mercado fizeram com que o desenvolvimento de novos produtos se traduzisse numa importante fonte de vantagem 
competitiva. É importante realçar que o desempenho deste processo depende da capacidade das empresas para gerir o processo de desenvolvimento de novos produtos e interagir com o mercado e com as fontes de inovação tecnológica. Este trabalho contribuiu para aprimorar o conhecimento dessa nova técnica de decoração que nos últimos 2 anos esteve em alta em todo o mundo, principalmente no Brasil. Onde diante dos resultados pode-se caracterizar suas tintas como partículas não nanométricas, porém com tamanhos inferiores a qualquer outro tipo de tinta de decoração usada nas indústrias de placas cerâmicas de revestimento, bem como, sua característica reológica apresentando baixas viscosidades para todas as tintas, até porque se faz necessário para este tipo de aplicação. Um paradigma de que a aplicação apresenta monotonalidade, pode ser melhor estudado, pois para este feito necessitaria de queima constante, que não é o caso das indústrias cerâmicas e que pode ser muito bem observado neste trabalho com variações de $\Delta \mathrm{E}$ de até 6 pontos perante a temperatura padrão de $1160{ }^{\circ} \mathrm{C}$ com variações de $40{ }^{\circ} \mathrm{C}$ tanto acima quanto abaixo desta temperatura. Mas mesmo com estas características ainda a impressão por jato de tinta se torna muito mais eficaz perante a qualquer outro processo de decoração, principalmente rotocolor. Com este trabalho foi possível detectar vários pontos importantes do processo de decoração por jato de tinta (Ink Jet), até então não explorados, trazendo aos técnicos e empresas uma contribuição mais aprofundada sobre $\mathrm{o}$ assunto.

\section{AGRADECIMENTOS}

$\mathrm{O}$ grupo agradece ao $\mathrm{CNPq}$, à CAPES e às empresas que apoiaram a realização deste trabalho.

\section{REFERÊNCIAS}

[1] I. Hutchings, Ceram. Ind. 15, 2 (2010).

[2] J. M. Campos, P. Corma, J. López, F. Lucas, S. Pasquetto, V. Moreno, Ceram. Ind. 7, 3 (2002).

[3] V. S. Nandi, "Otimização do processo de moagem de engobes cerâmicos para produção de revestimento", Trabalho de conclusão de curso (Tecnologia em cerâmica), Universidade do Extremo Sul Catarinense, Criciúma, SC (2009) 14f.

[4] Durst phototechnik AG, "Direct digital ceramic decoration systems", Brixen, Italy (2008).

[5] M. P. Pimenta, C. P. Melo, Parcerias Estratégicas 9, 18 (2004) 9-21.

[6] E. Rambaldi, A. Tucci, L. Esposito, D. Naldi, G. Timellini, "Efectos de los óxidos de partículas nanométricas sobre las propiedades superficiales de baldosas", Centro Cerâmico Bologna (2010), disponível em: <http:// aulavirtual. camaracastellon.com/qualicerCD/pdf/2010142. pdf $>$, acesso em 10/2011.

[7] P. M. T. Cavalcante, M. Dondi, G. Guarini, M. Raimondo, G. Baldi, Dyes and Pigments 80 (2009) 226-232.

(Rec. 14/11/2014, Ac. 30/04/2015) 